\title{
MIDAS
}

Museus e estudos interdisciplinares

$3 \mid 2014$

Varia e dossier temático: "Museos y participación biográfica"

\section{Un quehacer cotidiano: Proyecto de mediación de la exposición hacer en lo cotidiano}

An everyday chore: Mediation project from the exhibition hacer en lo cotidiano

David Lanau y Eva Morales

\section{OpenEdition \\ Journals}

\section{Edición electrónica}

URL: http://journals.openedition.org/midas/506

DOI: $10.4000 /$ midas.506

ISSN: 2182-9543

\section{Editor.}

Alice Semedo, Paulo Simões Rodrigues, Pedro Casaleiro, Raquel Henriques da Silva, Ana Carvalho

\section{Referencia electrónica}

David Lanau y Eva Morales, « Un quehacer cotidiano: Proyecto de mediación de la exposición hacer en lo cotidiano », MIDAS [En línea], 3 | 2014, Puesto en línea el 09 junio 2014, consultado el 01 mayo 2019. URL : http://journals.openedition.org/midas/506 ; DOI : 10.4000/midas.506

Este documento fue generado automáticamente el 1 mayo 2019.

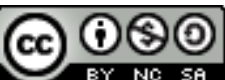

Midas is licensed under a Creative Commons Attribution-NonCommercial-ShareAlike 3.0 International License 


\section{Un quehacer cotidiano: Proyecto de mediación de la exposición hacer en lo cotidiano}

An everyday chore: Mediation project from the exhibition hacer en lo cotidiano

David Lanau y Eva Morales

\section{Introducción}

1 La mediación en centros de arte es relativamente nueva; no hay un único término que la defina o una metodología que la enmarque. Desde Pedagogías Invisibles (PI) nos proponemos analizar y experimentar con este termino, llevándolo a la práctica a través de la exposición hacer en lo cotidiano ${ }^{1}$.

2 Sí analizamos el término mediación, éste suele presuponer la existencia y necesidad de resolución de un conflicto. Pero, ¿cómo entendemos conflicto en nuestro caso? ¿Y cuáles son las partes del conflicto? Nosotras ${ }^{2}$ nos alejamos de la idea de que el arte contemporáneo y el espectador son las partes del conflicto, y de que la educadora es la encargada de llegar a un entendimiento entre ambas partes. No entendemos la práctica mediadora dentro de las instituciones culturales únicamente como generadora de interrogantes, sino como promotora de crear una relación experiencial entre el visitante y el conjunto de la exposición (Olaiz Soto y Soria Ibarra 2009). Por tanto podríamos intuir el conflicto como un malestar, pero no ante el arte contemporáneo en sí mismo sino ante una situación incómoda que se desprende de estar con desconocidos, de una falta de familiaridad: llegar a un lugar nuevo donde las obras y la sala pueden ser desconocidas para el visitante, y los visitantes pueden ser desconocidos para la sala y las obras. Y tal vez, entonces, el papel de la mediación sea romper el hielo; generar confianza y sentimiento de libertad; posibilitar que se creen diversas experiencias. 
Pero no sólo vemos el conflicto en estos términos, sino que para nosotras la visibilización del público como agente que forma parte del proceso de producción cultural nos parece el objetivo principal a mediar. Entendemos que todos los que compartimos una experiencia o un intercambio (instituciones, visitantes, artistas, comisarios...) somos creadores de cultura (Juanola y Colomer 2005) y nos parece fundamental la creación de dispositivos que permitan la posibilidad de visibilizar ${ }^{3}$ este hecho.

\section{Nos presentamos}

Nosotras somos PI, un colectivo de investigación y acción en torno al arte y la educación. Trabajamos desde el cuestionamiento de nuestro propio hacer y estar en los distintos ámbitos en los que actuamos, lo que nos lleva a abandonar los roles y fórmulas tradicionales y lidiar con la incomodidad e incertidumbre que supone el salirse de las zonas de confort.

5 En contextos expositivos de artes visuales estamos ensayando formas de mediación en las que se visibilice que el público forma parte del proceso de producción cultural.

\section{Desde dónde hablamos y por qué hablamos desde aquí}

6 Todo el texto tiene un carácter narrativo y experiencial, posicionándonos en la primera persona del femenino plural para hablar desde ahí. La experiencia vivida y presentada se transforma en un relato biográfico de las propias autoras, ya que nos basamos en las metodologías de enfoque cualitativo que contemplan la propia psique del investigador y del lector (Acaso 2011), donde no hay una realidad que pueda ser verificada de manera sólida, y siendo conscientes de los procesos interpretativos y fluidos que genera el lector. Por ello nos basamos en la experiencia situada, concepto que surge de la teoría feminista que considera que el conocimiento está siempre vinculado con las experiencias vividas de un sujeto (Acaso, Ellsworth y Padró 2011). Desde aquí buscamos que sea el lector quien genere su propio conocimiento y reflexiones y no extraer unas conclusiones cerradas, como afirma Wolcott (2003).

\section{Colocamos el escenario}

7 La Sala de Arte Joven de la Comunidad de Madrid es un espacio que busca promover a jóvenes artistas y comisarios. Cada año acoge el proyecto ganador del concurso Se busca comisario. En la edición del año 2013 la propuesta seleccionada fue la presentada por Beatriz Alonso: hacer en lo cotidiano.

8 Articulado en torno a dos exposiciones y una programación de actividades, conciertos y talleres, hacer en lo cotidiano quería reflexionar sobre la capacidad transformadora del arte en el día a día. Este proyecto curatorial estaba inspirado en la investigación que realizó Certeau et al. y que publicó en el libro La Invención de Cotidiano I. Artes de Hacer ([1996] 1999). La primera exposición buscaba destacar lo cotidiano a través de obras que se servían para ello de la descontextualización, la fragmentación o la metáfora de lo ordinario, pretendía descubrir esa «cosita extra» que diferencia lo ordinario de lo extraordinario 
(Alonso 2013, 36). Incidir en lo cotidiano era el eje de la segunda exposición que recogía obras en las que los artistas invitaban a reflexionar sobre la transformación y modificación de la vida diaria a través de pequeños gestos. ${ }^{4}$

\section{Cómo pensamos desarrollar nuestra práctica}

9 Cuando Beatriz Alonso nos propuso hacernos cargo de la mediación de hacer en lo cotidiano , lo tomamos como un reto ya que nos estábamos embarcando en un proyecto en el que el foco se desplazaba de la exposición hacia la experiencia, la reflexión, y la producción de conocimiento. Como mediadoras no se trataba de ser reproductoras de discursos ya construidos, sino productoras de pequeños relatos y facilitadoras de la visibilización del público en este proceso.

Desde la propia propuesta curatorial, se entendía la exposición como un dispositivo más junto con los talleres, conciertos y mediación para crear conocimiento y reflexionar sobre los conceptos en los que se enmarcaba el proyecto. Se alejaba, por lo tanto, de la idea de la exposición como epicentro de la producción cultural y se nos entendía a las mediadoras y los visitantes como unos agentes más creadores de cultura y conocimiento. Nos estábamos basando en un modelo transformativo donde todos los agentes éramos participes activamente (Morsch 2009).

11 Con este posicionamiento, nos planteamos un quehacer cotidiano trabajando desde las actividades que habitualmente se ofrecen en los programas de mediación en centros de arte, y si hay algo cotidiano en ellos son las visitas que se realizan en ellos para conocer sus colecciones o exhibiciones. Por ello, decidimos centrar nuestra propuesta en la realización de visitas a las dos exposiciones de hacer en lo cotidiano. Ahora bien, en consonancia con la poética del proyecto y nuestro posicionamiento, nosotras también queríamos destacar e incidir en esta cotidianeidad que son las visitas dentro de los contextos expositivos de artes visuales.

12 El carácter propio de este proyecto facilitó que entre Beatriz Alonso, los artistas y nosotras se mantuviese un diálogo abierto y propositivo. Pensamos diferentes estrategias para llegar a cumplir con nuestros objetivos, manteniendo un constante proceso de análisis y revisión.

13 Nuestra primera consideración fue huir del término visitante y sustituirlo por invitado, ya que éste implica una cercanía, acoger a alguien en tu hogar a quien das la bienvenida y con quien pretendes compartir un tiempo; de esta forma situábamos la sala como el hogar que visitar.

\section{Dividimos la organización de la mediación en cuatro partes diferenciadas.}

14 Lo primero para nosotras era conocer a los invitados que se acercaban a la sala (previa concertación de la visita); lo fundamental era presentarnos y conocer nuestros nombres. Seguidamente desarrollábamos lo que denominamos acción-umbral; pensamos realizar como acto introductorio una acción que nos alejara del discurso unidireccional y explicativo donde se presenta a los visitantes la exposición, su intención, el comisario, etc. Mediante la acción pudimos alejarnos del diálogo comunicativo y lineal y adentrarnos en el diálogo analítico que propone Ellsworth y Prats (2005), un diálogo que acepta la 
imposibilidad de la comprensión total de un discurso y a partir de cuyas fracturas se llega a la construcción de un conocimiento propio. Diseñamos dos acciones, una para cada exposición, que explicaremos más adelante.

Después de esta acción pasábamos a una exploración libre; era el momento en el que cada invitado se acercaba libremente a las obras expuestas y tenía una primera impresión del conjunto de la exposición. A continuación entre todos decidíamos por qué obra comenzar la exploración conjunta donde el objetivo principal era que, a partir de un diálogo analítico, pudiéramos entre todos ir construyendo y reflexionando sobre las propuestas artísticas. Una vez terminada la exploración conjunta, recogíamos nuestra experiencia mediante la realización de los mapas conceptuales donde visibilizaríamos la producción cultural que habíamos producido.

16 A continuación pasamos a narrar nuestra experiencia.

\section{Un quehacer cotidiano (nuestra experiencia)}

17 La Sala de Arte Joven, para quienes no la conozcan, tiene unos enormes ventanales que nos alejan del cubo blanco y han permitido que lo cotidiano de la exposición y lo cotidiano de la calle estuvieran en contacto y se reflejaran en el cristal que los separaba y los conectaba. En este proyecto el espacio estaba articulado para resultar cercano y acogedor. La zona de talleres no estaba escondida en un lugar aparte sino justo junto a la entrada, enfrente de los ventanales, en la parte más visible de toda la sala e integrada dentro de la propia exposición. Esta zona estaba compuesta por unas mesas y taburetes que se podían mover, ajustar y transformar al gusto del visitante, acompañadas de unos bancos con cojines de patchwork que invitaban a sentarse, algunas plantas y pequeñas 
lámparas de mesa. Todos estos elementos hacían de este lugar un híbrido entre una exposición, una sala de estar y un taller de actividades.

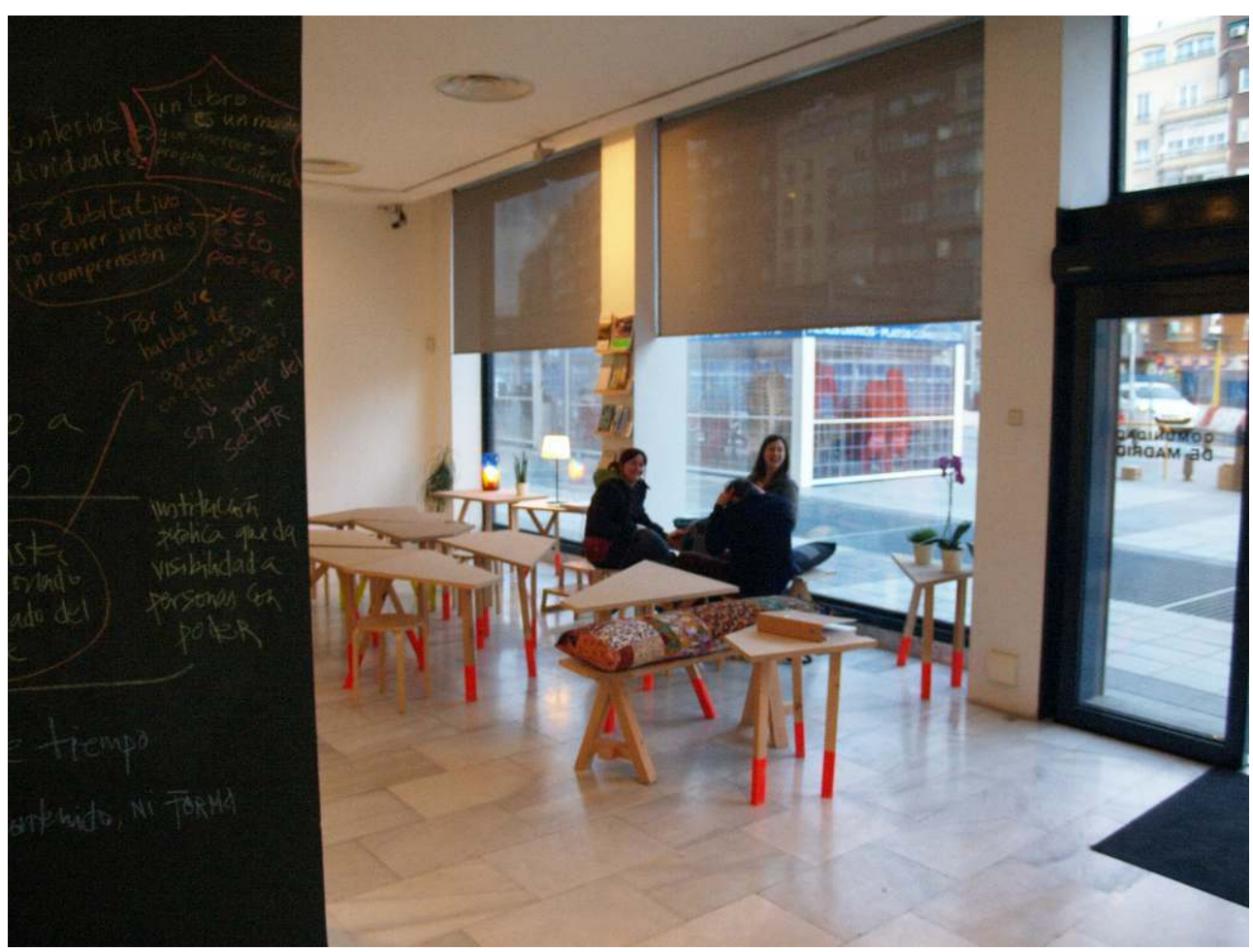

Fig. 1 - Zona de taller y entrada de la exposición

(c) Pedagogías Invisibles

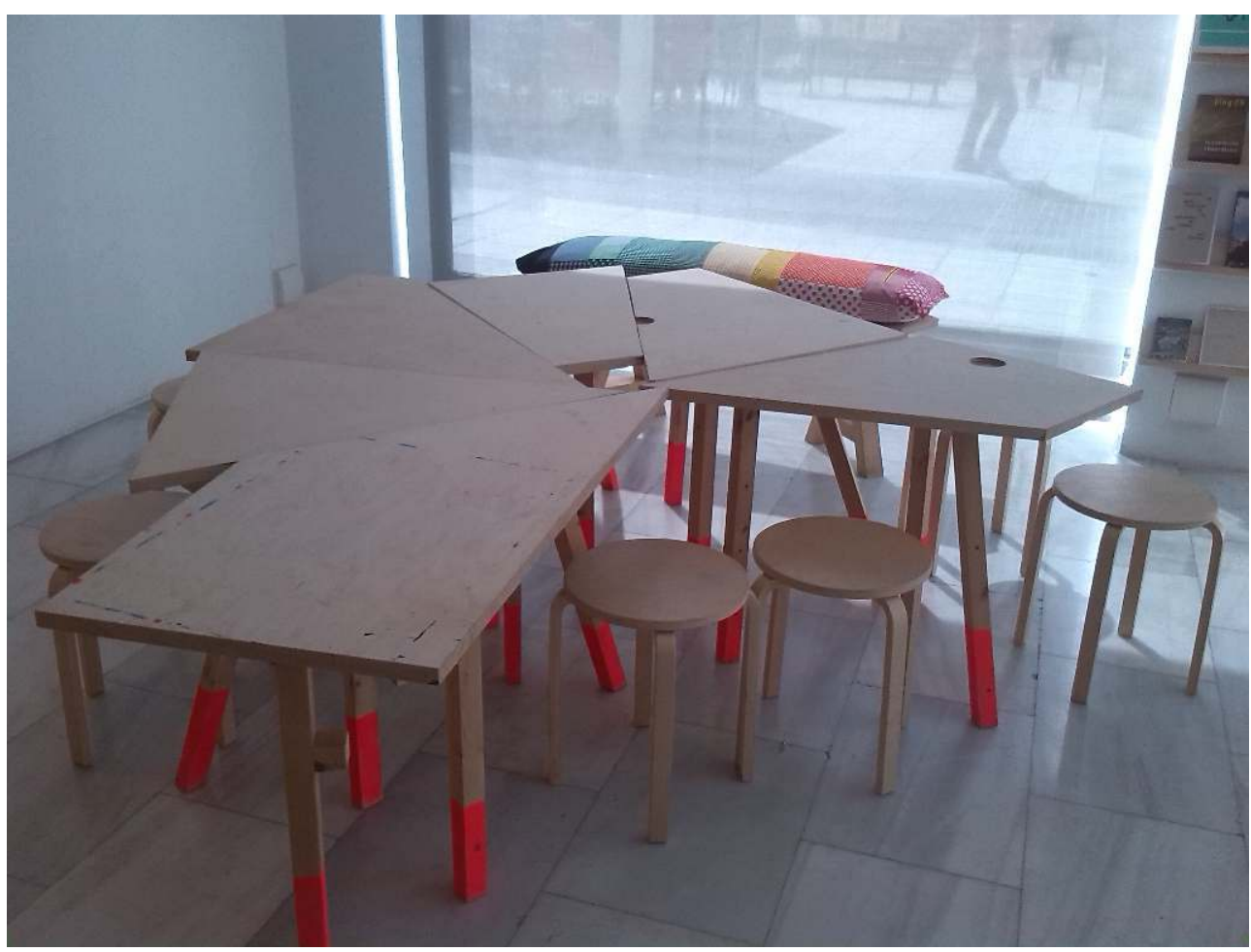

Fig. 2 - Las mesas, bancó y sillas

(c) Pedagogías Invisibles 

como un día fijo para ofrecer visitas a la sala, y entre semana dejábamos abiertos los días y el horario de visita según la demanda de los grupos. Así, sin fijarlos de modo rígido, fueron surgiendo unos horarios habituales $y$, junto a ellos, unas rutinas. Siempre llegábamos unos quince minutos antes de empezar la visita para preparar todo lo que hiciera falta. - Buenos días (buenas tardes) Fernando, ¿qué tal todo? - Saludábamos al vigilante de la sala e íbamos al almacén a dejar nuestras cosas. De pasada, nos fijábamos en la pared de pizarra que había en la entrada y comprobábamos si alguien había dejado algún comentario, escrito o visual, sobre su experiencia de la exposición; si era así, tomábamos una foto para tener el registro y añadirlo a nuestro libro de visitas. invitados, aunque en alguna ocasión ya estaban ellos esperándonos a nosotros; unos invitados muy especiales ya que en la mayoría de las ocasiones no nos conocíamos. Según llegaban entraban en la sala les invitábamos a sentarse junto a nosotros:

20 - Hola, somos David y Eva, ¿venís a la visita?

21 - Sí, hablamos por mail.

22 - Genial. Si queréis podemos sentarnos alrededor de las mesas, en los taburetes y el banco, y vamos presentándonos todos.

Saber nuestros nombres (aunque luego la memoria nos fallara y necesitáramos un recordatorio) nos parecía fundamental para ir creando esa sensación de familiaridad que perseguíamos.

Una vez que nos habíamos presentado y estábamos acomodados teníamos que ir entrando en la exposición. En bastantes ocasiones entramos en una sala de exposiciones y esperamos que comience la visita sin que el cruzar la puerta, hojear el folleto y los minutos de espera nos sirvan para dejar fuera todo el ruido, la saturación sensorial, la mirada distraída, los gestos automáticos con los que nos desenvolvemos. Por eso, pensamos en crear unos umbrales, espacios híbridos, que atravesar con el cuerpo y la mente realizando una acción; acciones-umbral que sirvieran de transición hacia otro modo de estar y que constituyeran una inmersión en la poética de la exposición.

Así, en hacer en lo cotidiano 01 la acción-umbral consistía en elegir un objeto que hubiéramos traído con nosotros y nos pareciera interesante mostrar al resto del grupo, presentarlo. Cargados como vamos siempre de multitud de cosas parecía que todas ellas desaparecieran porque el comentario: - Ummm..., yo es que no llevo nada; no sé qué enseñar - se repetía frecuentemente. La situación cambiaba cuando una de nosotras dos (David o Eva) presentábamos el bono metro, las zapatillas que llevábamos, el móvil... ¡Ah...! - se oía de modo casi imperceptible cuando el resto de participantes veían que la cuestión era mucho más simple ya que no se trataba de mostrar algo muy especial que lleváramos, sino de prestar atención a algo mínimo que trajéramos con nosotros $\mathrm{y}$, tal vez, de modo tan habitual que se hubiera hecho invisible de puro cotidiano. Y como el objetivo era prestar atención a ese sencillo objeto elegido por cada uno de nosotros (y escuchar por qué habíamos decidido presentar ese objeto en concreto, qué uso hacíamos de él, si era algo que solíamos llevar encima habitualmente...), parecía necesario darle el lugar que lo pusiera en valor, que lo encuadrara, y para ello tomábamos prestado uno de los marcos de la obra de una de las artistas. Así teníamos nuestro sencillo objeto cotidiano enmarcado para enfocar nuestra mirada; sacarla de su distracción. Y junto con el objeto 
elegido por cada uno surgían un montón de pequeñas historias, hábitos, rutinas que lo acompañaban y contaban algo de nosotros.

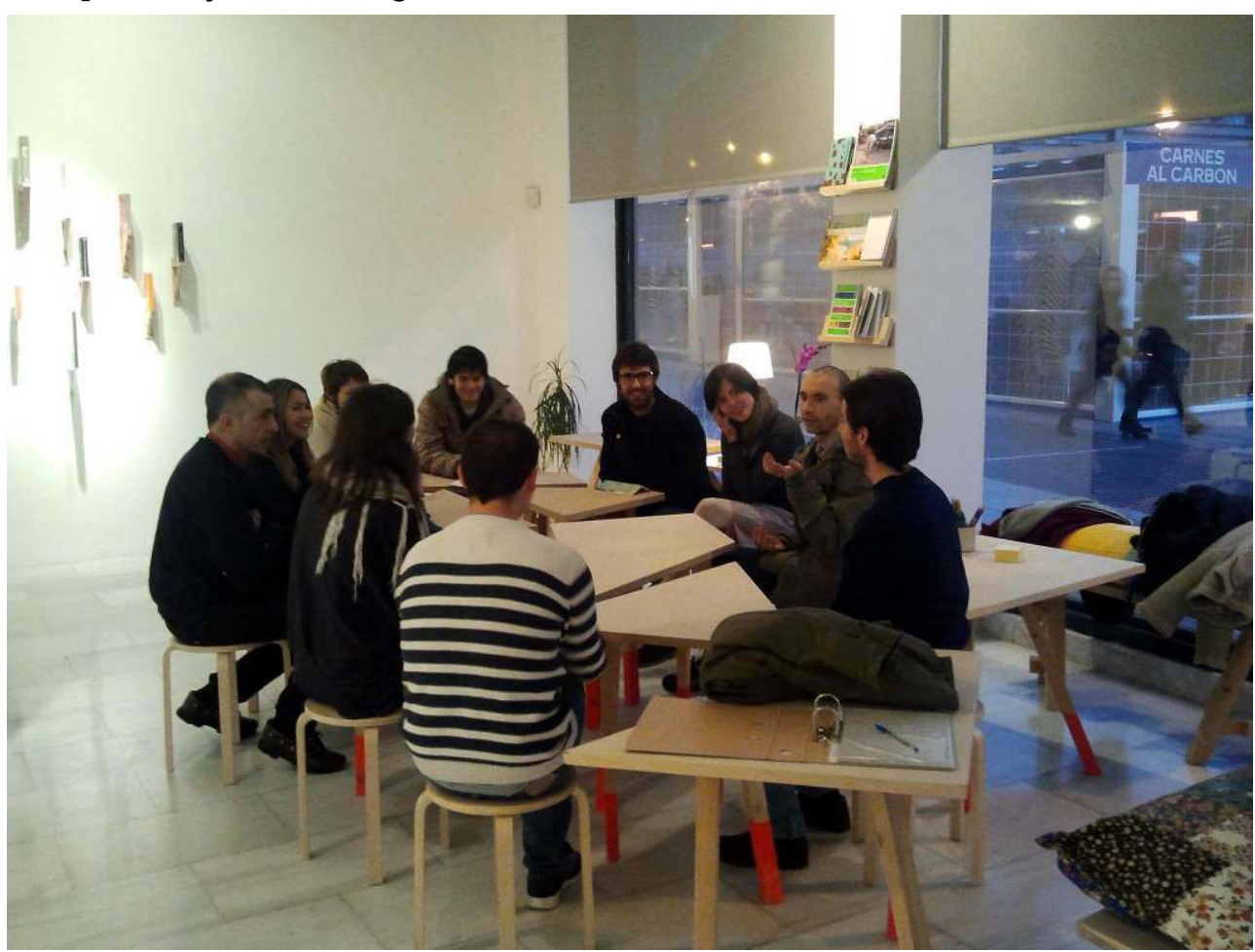

Fig. 3 - Acción-umbral hacer en lo cotidiano 01

(C) Iván García

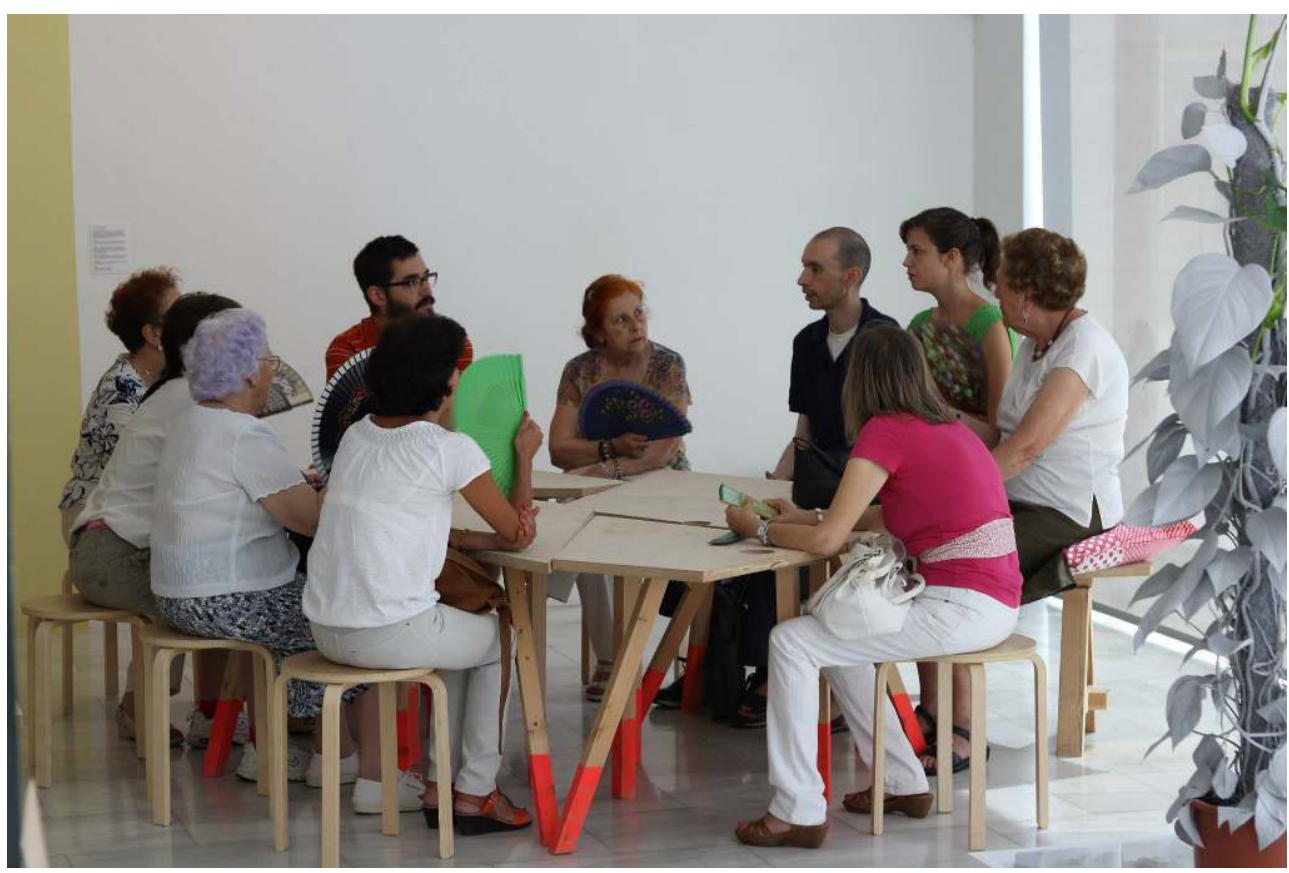

Fig. 4 - Acción-umbral hacer en lo cotidiano 02

(c) Iván García

Para hacer en lo cotidiano 02 pensamos en una acción de inicio que invitara a incidir sobre nosotros mismos a través de sencillas estrategias como quitarnos o cambiar de posición alguna prenda u objeto que lleváramos encima, darle otro uso, intercambiar algo con otra 
persona... No tenía que ser nada muy llamativo (aunque no poníamos límite), tal vez pasara desapercibido para alguien que no hubiera estado en esta dinámica inicial, pero lo importante era que, de alguna manera, habíamos incidido en lo cotidiano de nuestro atuendo, de las cosas que normalmente nos acompañan, de los gestos y costumbres habituales. Así, nos pusimos la camisa del revés, nos quitamos los pendientes, anduvimos descalzos, nos sacamos los cordones de una zapatilla, nos colocamos una rebeca a modo de mandil... Y entonces se trataba de realizar la visita manteniendo el cambio que habíamos hecho, ¿cómo nos afectaría? ¿No nos daríamos ni cuenta o llegaría un momento en el que nos sentiríamos realmente incómodos?

Al realizar estas acciones no hacíamos explícita a priori nuestra intención de que éstas propiciaran un acercamiento al tema conductor de la exposición, por lo que asumíamos que podían suponer un punto de extrañamiento e incluso de absurdo para los participantes. Sólo tras la realización de las acciones apuntábamos a las ideas de destacar o de incidir que subyacían a estos gestos. Desde esta insinuación, era el momento de salir de nuestro espacio en torno a las mesas y ver qué había en la sala; se trataba de explorar la exposición y las obras; una exploración breve, unos 15 minutos, como cuando echas un primer vistazo al bufet de un restaurante y empieza a abrirse el apetito.

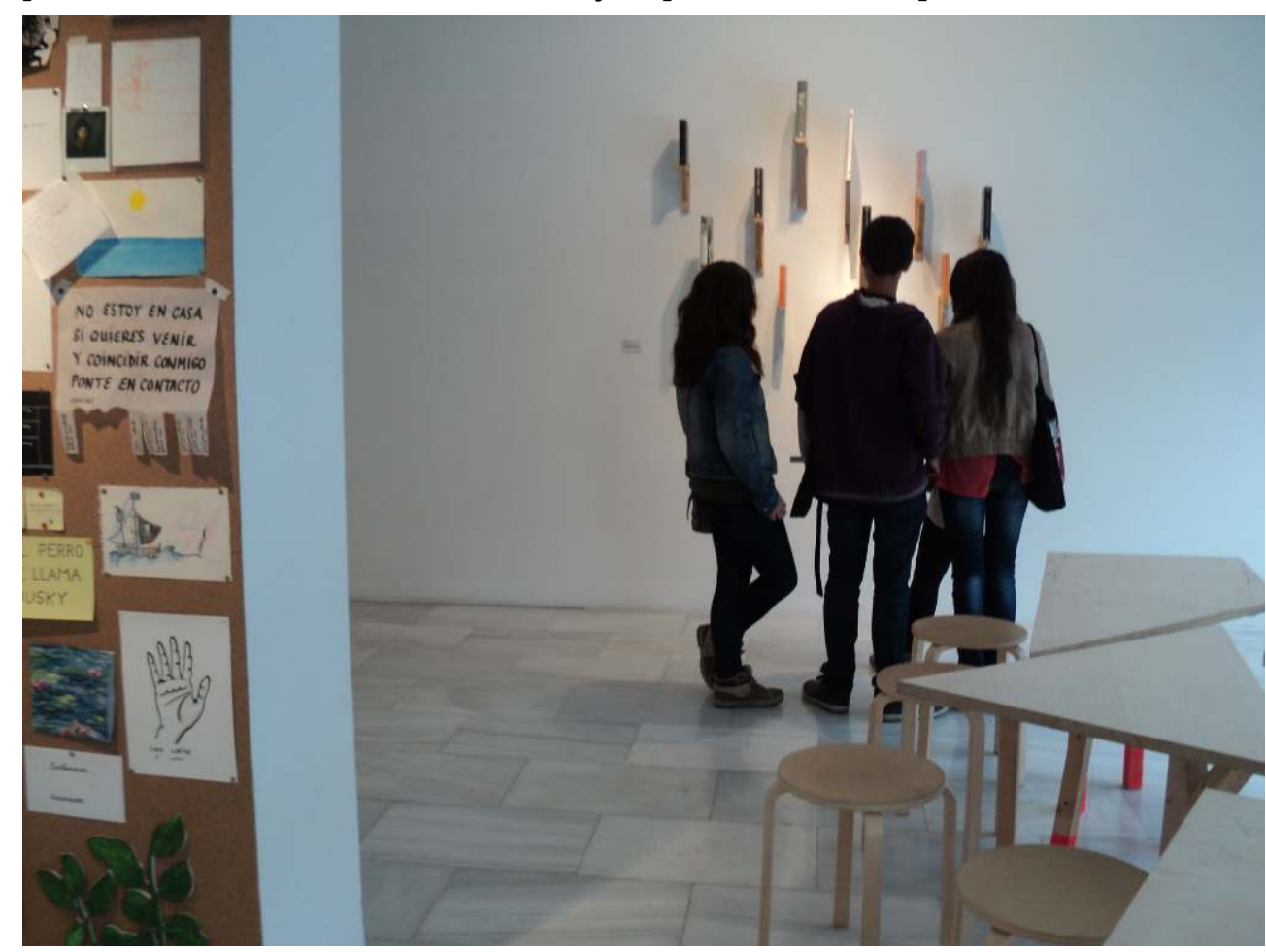

Fig. 5 - Exploración breve de 15 minutos en hacer en lo cotidiano 01

(c) Alicia Roy

Este tiempo de exploración no sólo nos llevaba a echar un primer vistazo a las obras; era un deambular por la sala; empezar a familiarizarse con ella, con sus rincones; era tener en cuenta la importancia del espacio como elemento mediador de una experiencia y la necesidad de dedicarle un tiempo. Era, también, dejar que cada uno de nosotros realizara un itinerario físico y mental individual en el que nos cruzáramos en algunos puntos y, en otros, fuéramos cada uno por nuestro lado. En hacer en lo cotidiano 02, especialmente, se trataba de una auténtica exploración del mismo espacio expositivo, de desviarse de los lugares habituales de exposición y buscar o encontrar en sitios inesperados. 
do ese momento de curioso deambular, nos juntábamos de nuevo y nos sentábamos alrededor de ese grupo de mesas transformable según nos quisiéramos colocar, donde se formaban huecos y aristas entre los que buscábamos la forma de acomodarnos todos. De este modo, el simple hecho de sentarse, algo bien cotidiano, se convertía en una acción con el cuerpo que, por sutil que fuera, nos movía exterior e interiormente y nos predisponía a la acción, al movimiento físico y mental, a estar todos juntos desde posturas distintas, buscando nuestro espacio. $Y$ la pregunta que ineludiblemente, de modo lógico y natural, surgía era: «¿Qué os ha parecido?», acompañada de: «¿Alguna obra o algo que os haya llamado especialmente la atención?». No hacía falta más. Empezaban a descolgarse frases como: «A mí me han llamado la atención los panes»; «he oído en unos cascos el programa de radio que escucho todas las mañanas»; «yo, los montones esos»; «iyo también!»; «a mí el vídeo éste» - mientras un gesto señalaba una televisión... - Y así iban surgiendo alusiones a distintas obras que, de un modo $u$ otro, acababan definiendo un punto por el que empezar el recorrido en grupo, bien porque se repitieran ciertos comentarios, bien por la intensidad de la curiosidad que una obra hubiera provocado en alguien, o por un motivo tan prosaico como que, de todas las propuestas mencionadas, fuera de la que más cerca nos encontráramos. Ya teníamos un punto de inicio para empezar nuestro mirar conjunto y un montón de posibilidades para seguir. No definíamos previamente la ruta que íbamos a recorrer, sólo nos poníamos en marcha desde un punto de salida abiertos a que fuera el andar el que hiciera camino y definiera nuestras paradas.

Y, de este modo, comenzábamos a intentar poner palabras y decir en voz alta los interrogantes que la obra por la que habíamos decidido empezar, o aquélla hacia la que nos habíamos desviado, nos arrancaba. Íbamos trenzando lo que veíamos con lo que nos interrogaba, con la información que podíamos aportar, con las interpretaciones que ensayábamos, trabajando desde nuestra realidad cotidiana y entendiendo la obra como una pregunta abierta de modo preciso, hábilmente codificada de modo visual y que puede ayudarnos a entender mejor los mundos sociales y culturales en los que nos desenvolvemos. Así que no se trataba de dejar las cosas claras, sino de desenfocar la mirada para posibilitar nuevas miradas. 


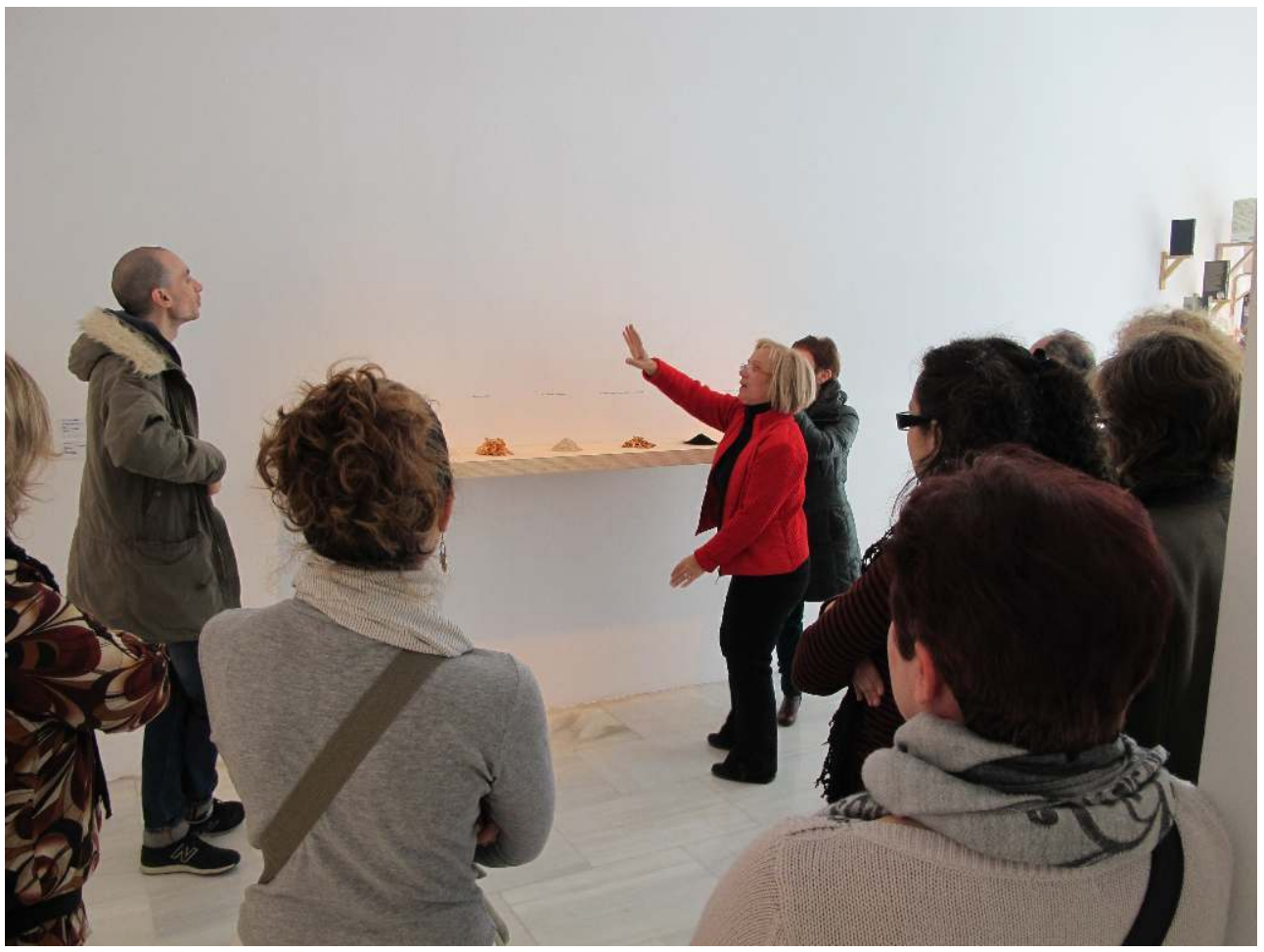

Fig. 6 - Exploración conjunta en hacer en lo cotidiano 01 (c) Iván García

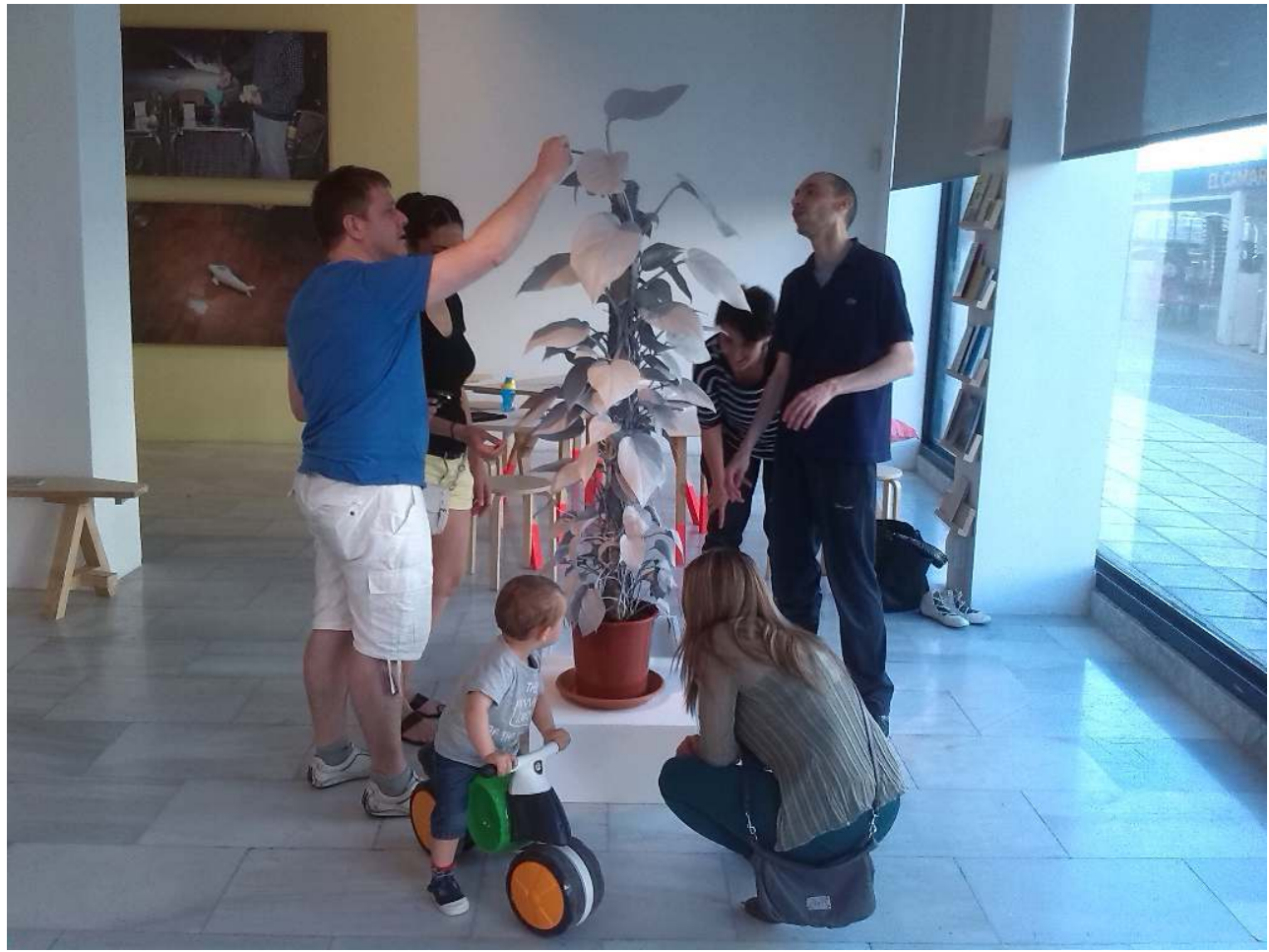

Fig. 7 - Exploración conjunta en hacer en lo cotidiano 02 (c) Pedagogías Invisibles

31 Y de una obra pasábamos a otra, ¿cómo? Pues, retomando la metáfora del bufet, con la misma naturalidad con la que después de un tazón de cereales nos apetece tomar un poco de fruta o el aparente desorden con el que volvemos a tomar un poco de fiambre después 
de haber terminado el café con bizcocho; sintaxis lógicas o quebradas con las que íbamos articulando los pequeños relatos de las visitas. Pequeños relatos que fueran nutritivos y no acabaran empachándonos, por eso renegamos de un consumo bulímico, de una visita en la que se vieran todas las obras sin haber llegado a ver ninguna, y eso obligaba a saber decir basta y renunciar a trabajar aquel día otras obras que «itenían tan buena pinta!»

Cada visita ha sido una experiencia única e irrepetible ya que en cada una hemos recorrido itinerarios distintos, aun cuando pudieran resultar muy parecidos a simple vista. No obsta esto para que nosotros dos (David y Eva), que hemos transitado todos estos caminos junto con las personas que han visitado la sala, fuéramos observando lugares comunes, puntos de encuentro, a todas las visitas.

Después de recorrer la sala la visita iba llegando a su fin: nos habíamos presentado, realizado una acción introductoria, explorado la exposición de modo individual y trabajado en grupo unas cuantas obras; con estas dinámicas incidíamos en el formato tradicional de la visita guiada. Pero aún nos faltaba un último punto que nos iba a servir para destacar esas visitas que han formado parte de la cotidianeidad de la sala durante estos meses; que dejaran huella. Y es que para terminar cada visita nos parecía fundamental visibilizar la experiencia y el conocimiento producido colectivamente a través de la creación de mapas visuales sobre ese interfaz que ha sido la pared de pizarra.

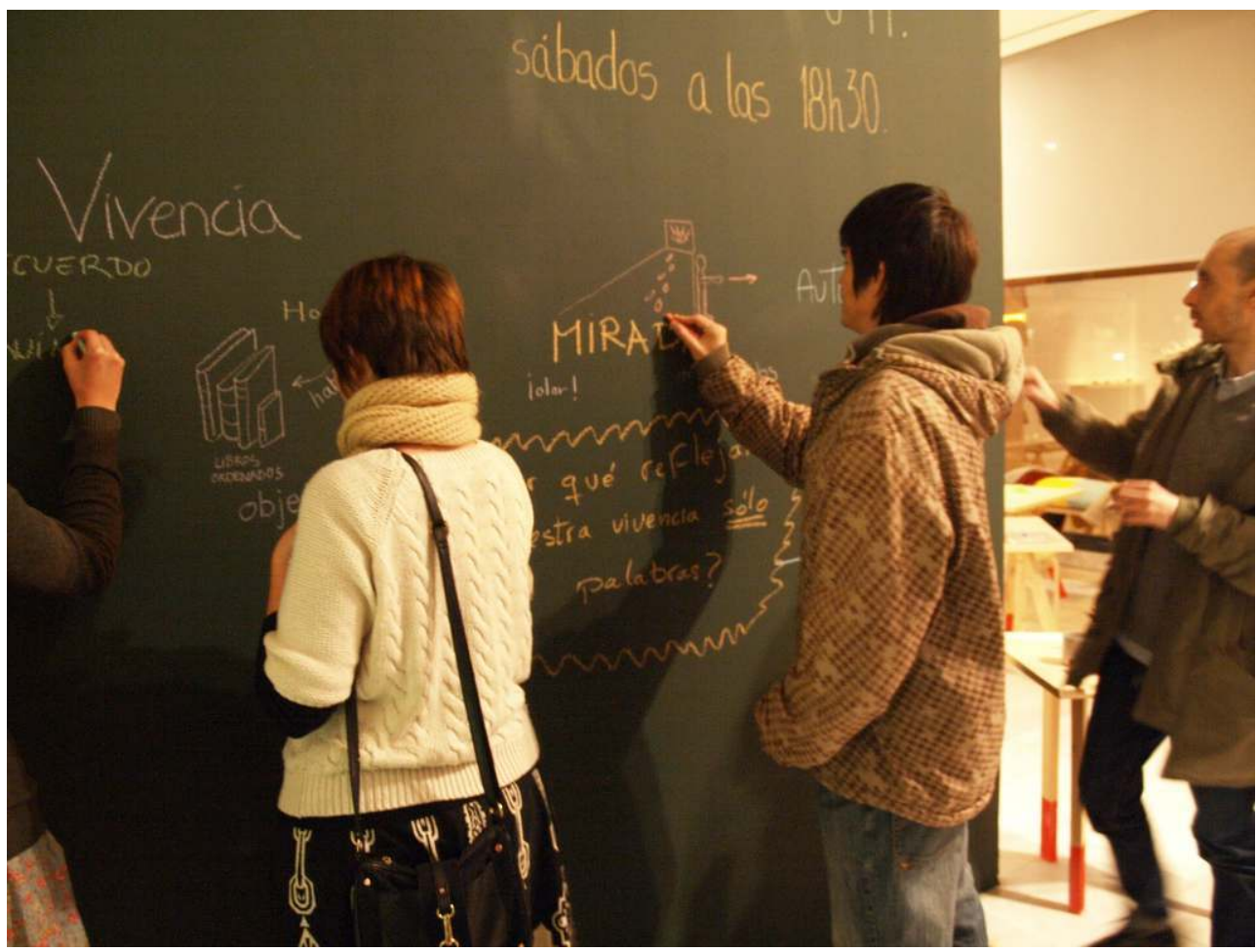

Fig. 8 - CREACIÓN DE MAPA VISUAL

(C) Pedagogías Invisibles 


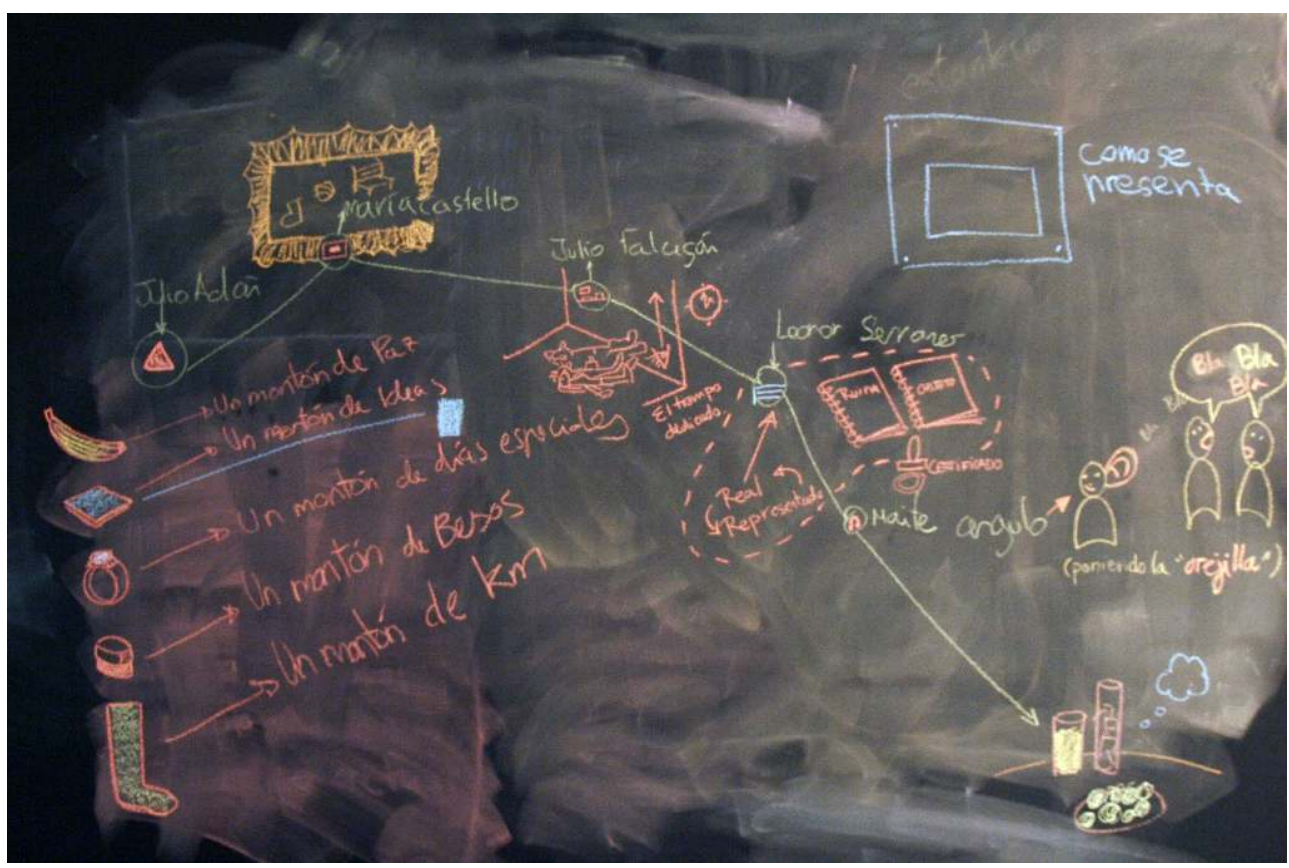

FIg. 9 - MAPA VISUAL

(c) Pedagogías Invisibles

34 Además, estas visibilizaciones efímeras quedaban recogidas en foto y pasaban a formar parte de nuestro libro de visitas, no como un testimonio muerto de lo que fue, sino como fotografías de una experiencia vivida que animara a otros visitantes a recorrer sus propios itinerarios y compartirlos. ${ }^{5} \mathrm{El}$ libro de visitas tenía vocación de funcionar como un dispositivo activo y no como un mero registro muerto, y por eso no acertaríamos a explicar la alegría que nos supuso comprobar que, aunque tímidamente, juncionaba!

35 Y ya sí que llegaba la hora de despedirse de las personas con las que habíamos compartido la exposición ese día. En ocasiones la despedida era calmada, con un par de besos y pensando en la próxima vez que nos veríamos; otras veces era Fernando quien nos indicaba que la sala se cerraba, así que íbamos corriendo a por nuestras cosas y terminábamos de despedirnos en la calle: habían pasado más de dos horas sin darnos cuenta. De camino al metro siempre una misma pregunta: «¿cómo has visto la visita de hoy?»

\section{Qué ha supuesto esta experiencia para nosotras (conclusiones)}

36 Cada día al salir de la sala analizábamos cómo habíamos desarrollado la mediación. Surgieron muchas cuestiones que no siempre tenían una única respuesta, ya que cada visita era una vivencia irrepetible y esas mismas preguntas que nos lanzábamos a nosotras mismas se respondían de múltiples formas cada día; por ello, una de las conclusiones que podemos extraer es que es un trabajo en constante proceso y transformación.

Las dinámicas que aplicamos nos ayudaron a llevar a cabo nuestro principal objetivo: visibilizar al público como productor cultural y generador de conocimiento. Para nosotras fue importante pasar a entender al público como invitados ya que este simple gesto 
implicaba una mayor cercanía. Gracias a realizar la acción-umbral y la exploración conjunta desde el diálogo analítico, tanto nosotras como los invitados pudimos ir construyendo nuestro propio relato, sin la intención de llegar a verdades únicas sino de articular una diversidad de múltiples miradas. La construcción de los mapas suponía dejar reflejado de una forma física todo lo acontecido y realmente visibilizar nuestra producción.

Desde esta experiencia y reflexión queremos ir un paso más allá: que nuestros invitados pasen a ser habitantes del proceso de producción cultural; ser habitante implica una permanencia y continuidad, ya que un invitado no deja de ser alguien que pasa y está temporalmente. Desde la mediación el nuevo reto al que nos queremos enfrentar es desarrollar dinámicas que hagan posible considerar a todos los agentes (comisaria, artistas, educadores, público...) habitantes permanentes de la producción cultural.

\section{BIBLIOGRAFÍA}

Acaso, Maria, Elizabeth Ellsworth, y Carla Padró. 2011. El Aprendizaje de lo Inesperado. Madrid: Los Libros de la Catarata.

Acaso, María. 2011. "Preguntas Retóricas." In Perspectivas: Situación Actual de la Educación en los Museos de Artes Visuales, coordinado por María Acaso, 133-159. Barcelona: Ariel.

Alonso, Beatriz, ed. 2013. Hacer en lo Cotidiano. [Madrid]: Consejería de Empleo, Turismo y Cultura de la Comunidad de Madrid. https://dl.dropboxusercontent.com/u/28694531/catálogo\%20hacer \%20en\%20lo\%20cotidiano.pdf

Bishop, Claire. 2006. Participation. Documents of Contemporary Art Series. London: MIT Press.

Cary, Richard. 1998. Critical Art Pedagogy: Foundations for Postmodern Art Education. New York: Garland.

Certeau, Michel de, et al. (1996) 1999. La Invención de lo Cotidiano I. Artes de Hacer. [Guadalajara]: Universidad Iberoamericana. Departamento de Historia: Centro Francés de Estudios Mexicanos y Centroamericanos; Instituto Tecnológico y de Estudios Superiores de Occidente.

Ellsworth, Elizabeth, y Laura Trafí Prats. 2005. Posiciones en la Enseñanza: Diferencia, Pedagogía y el Poder de la Direccionalidad. Madrid: Akal.

Haraway, Donna. 1991. Ciencia, Cyborgs y Mujeres: La Reinvención de la Naturaleza. Valencia: Cátedra. Hooper-Greenhill, Eilean. 1992. Museums and the Shaping of Knowledge. London: Routledge.

Juanola, Roser, y Anna Colomer. 2005. Museus y Educadores: Perspectivas y Retos de Futuro. In La Mirada Inquieta: Educación Artística y Museos, editado por Ricard Huerta e Romà de la Calle, 21-40. Valéncia: Universitat de València.

Mörsch, Carmen. 2009. Documenta 12. Education. Berlin: Zurich Diaphanes.

Olaiz Soto, Ilargí, y Fermín Soria Ibarra. 2009. El educador como mediador de un aprendizaje reflexivo. In Actas, Ponencias y Comunicaciones del I Congreso Internacional. Los Museos en la Educación: La 
Formación de los Educadores. Madrid: Museo Thyssen-Bornemisza. http://www.educathyssen.org/ fileadmin/plantilla/recursos/Investigacion/Congreso/Actas_ICongreso_total.pdf

Rancière, Jacques, y Ariel Dilon. 2010. El Espectador Emancipado. Castellón: Ellago Ediciones.

Rancière, Jacques, y Núria Estrach. 2003. El Maestro Ignorante. Barcelona: Editorial Laertes.

Ristock, Janice, y Joan Pennell. 1996. Community Research as Empowerment: Feminist Links, Postmodern Interruptions. Toronto: Oxford University Press.

Villeneuve, Pat. 2007. From Periphery to Center: Art museum Education in the $21^{\text {st }}$ Century. Reston: National Art Education Association.

Wolcott, Harry F. 2003. Mejorar la Escritura de la Investigación Cualitativa. Medellín: Universidad de Antioquia. Colección Contus.

\section{NOTAS}

1. El título original del proyecto es hacer en lo cotidiano, escrito en minúsculas.

2. Utilizamos el termino nosotras desde el femenino plural ya que nos situamos dentro del pensamiento feminista y desde el paradigma propuesto por Haraway (2009) en el capítulo «Conocimientos Situados: La cuestión Científica en el Feminismo y el Privilegio de la Perspectiva parcial» del libro Ciencia, Cyborgs y Mujeres.

3. Utilizamos el termino visibilizar en referencia a «hacer visible». Véase: http://lema.rae.es/ drae/?val=visibilizar.

4. Para obtener más información sobre la exposición consultar Alonso (2013).

5. En la primera página del libro de visitas un breve texto explicaba la intención de éste: «Cada visita en grupo a la exposición es una experiencia de aprendizaje en la que recorremos itinerarios físicos y mentales distintos dependiendo de los interrogantes, comentarios, intereses que van surgiendo. En estos ratos de cotidianeidades compartidas se van produciendo unos vínculos, un conocimiento, que merecen dejar huella en este espacio común, por eso siempre terminamos las visitas haciendo un mapa. Te invitamos a que los curiosees - tal vez te sirvan como detonante -, intervengas sobre ellos, o dejes tu propia cartografía de la exposición.»

\section{RESÚMENES}

El presente artículo tiene como principal intención reflexionar acerca del termino mediación y su práctica, a través de la experiencia que Pedagogías Invisibles, colectivo de investigación y acción en torno al arte y la educación, desarrolló en el proyecto expositivo hacer en lo cotidiano durante los meses de febrero a septiembre de 2013. Desde Pedagogías Invisibles, entendemos que no hay una única metodología para practicar la mediación y queremos presentar nuestra forma de hacer. Nosotras a través de la mediación nos proponemos como principal objetivo visibilizar al público como parte del proceso de producción cultural, y proponemos entender la mediación como un lugar para el encuentro de reflexiones, de experiencias y de producción de conocimiento entre las obras de los artistas, el público, el discurso curatorial y los educadores. 
This article intends to assess the terminology 'mediation' as well as its practice, through the experience that Invisible Pedagogies - a research and action arts education collective developed for the exhibition "Everyday Doings" (hacer en lo cotidiano) between February and September 2013. At Invisible Pedagogies, we believe in multiple methodologies in enacting mediation and we want to introduce our own practices. Our main concern is to render the public visible as one of the agents involved in the cultural production process, understanding the act of mediation as the creation of a space for encounters, reflections, experiences and knowledge production generated between the works of art, the public, the curatorial discourse and the educators.

\section{ÍNDICE}

Keywords: mediation, museum experience, participation, learning, Invisible Pedagogies Palabras claves: aprendizaje, mediación, participación, experiencia museo, Pedagogías Invisibles

\section{AUTORES}

\section{DAVID LANAU}

Licenciado en Humanidades y especializado en Educación Artística. Miembro del colectivo de arte y educación Pedagogías Invisibles, diseña y ha desarrollado proyectos educativos para museos e instituciones culturales como la Fundación Juan March, Matadero Madrid, Sala de Arte Joven de la Comunidad de Madrid, Fundación Barrié y Espacio Fundación Telefónica. En el ámbito universitario, es profesor colaborador en el Máster de Diseño y Gestión de Exposiciones de la Universidad Europea de Madrid. En la actualidad, escribe su tesis titulada Cartografía de las Infraestructuras de la Visita Guiada para Adultos en Contextos Expositivos de Madrid.

\section{EVA MORALES}

Licenciada en Bellas Artes por la Universidad Complutense de Madrid. Se denomina a sí misma Educadora Nómada ya que ha realizado y realiza su práctica profesional en diversas instituciones: el Museo Thyssen-Bornemisza, Manifesta 8, o la Fundación Botín. Es miembro del colectivo Pedagogías Invisibles donde diseña y desarrolla diversos programas educativos y de investigación en arte y educación. Forma parte del colectivo artístico Núbol. Actualmente realiza su tesis doctoral Nuevos Formatos para el Aprendizaje en Centros de Arte Contemporáneo: De los Talleres de Familia a las Acciones Intergeneracionales. 